\title{
Atitude Natural e Fenomenológica em Husserl
}

Rafael Gargano

\section{Resumo:}

O estudo da fenomenologia husserliana é, sem dúvida, penoso, seja pelo imenso aparato conceitual da obra, seja porque uma nova maneira de fazer filosofia nasce de seus livros e trabalhos inéditos. As estruturas da sua fenomenologia estão organizadas de tal forma que é impossível tratar de questões como existência, consciência, intencionalidade, constituição, redução, percepção e essência sem compreender de maneira clara a distinção entre atitude natural e atitude fenomenológica. Essa distinção nos possibilitará compreender qual o rumo dado à fenomenologia husserliana.

Palavras chave: fenomenologia - redução - atitude natural - atitude fenomenológica - consciência. 
Este artigo pretende esclarecer um dos momentos mais importantes da filosofia husserliana e da fenomenologia, a distinção entre atitude natural e atitude fenomenológica, propostas de forma clara nos Problemas fundamentais da fenomenologia. ${ }^{\mathrm{I}}$ Tais atitudes dizem respeito à maneira como me posiciono frente ao mundo, o ponto de partida que assumo para conhecê-lo. Na atitude natural, partimos de uma realidade dada em si mesma, fechada sobre si e totalmente determinável. A coisa natural está aí para mim, ela me é transcendente. Por outro lado, eu estou aqui, com meu corpo e meus sentidos para poder experienciá-la. Na atitude fenomenológica, há uma mudança de postura frente ao mundo. As coisas que vejo não são mais essas dadas em si mesmas, realidades exteriores a mim, mas correlatos da minha consciência. Nessa correlação fundase o próprio aparecer da coisa.

Que entender por atitude natural? Ela deve ser compreendida, conforme Husserl, como uma "atitude de experiência", que coloca a experiência e funda nela seus juízos. Há, nessa atitude, uma descrição do imediatamente dado, uma descrição do "experenciado, do meramente encontrado" (HUSSERL, I994, p. 56). Nela, o eu poderá experimentar-se, ter experiência das coisas e dos outros corpos. Por isso, ao abrir a exposição da atitude natural nos Problemas..., Husserl ressalta a primeira experiência que se tem nessa atitude, a saber: "cada um de nós diz eu, e se conhece, por assim dizer, como eu" (HUSSERL, I994, p. 48). Encontra-se como tal e ao mesmo tempo como centro de um entorno" (HUSSERL, I994, p.48). Esse primeiro momento é característico, pois ao mesmo tempo em que me encontro enquanto eu, já me é dado um entorno. Em outras palavras, já me encontro situado no mundo.

Ao mesmo tempo em que realiza a experiência mais fundamental, o eu se encontra como portador de um corpo que aparece como seu revestimento. $\mathrm{O}$ que entender aqui por corpo? Husserl afirma que o corpo é uma "coisa espaçotemporal ao redor do qual se agrupa um entorno coísico que se estende sem limites" (HUSSERL, I994, p. 49). O corpo orgânico é aquele que se apresenta como uma coisa física e biológica, dotado de órgãos, aparelho sensorial etc. Em contrapartida, o corpo próprio é o modo de relação com o entorno objetivo, que se distingue do corpo próprio pelo modo como percebo cada um deles. O corpo aparece enquanto meu corpo, numa proximidade que permite sentilo enquanto me sinto, percebendo-o enquanto coisa que sente e coisa que é sentida. Ao contrário, os objetos do mundo são percebidos por mim, posso tocá-los, modificá-los, mas não consigo senti-los como sinto meu corpo. Estão distante de mim. De fato, o corpo próprio "sempre e inevitavelmente se encontra aí em uma esfera perceptiva atual" (HUSSERL, I994, p. 50), e aquilo

I Lições ministradas no semestre de inverno de I9IO-II. 
que não está nessa relação de proximidade inevitável aparece sempre em relação a ele com certa orientação espacial.

Essas experiências que me são dadas na atitude natural não seguem numa sequência cronológica, pois ao mesmo tempo em que me encontro enquanto eu, já me encontro também enquanto corpo situado no espaço e tempo, cercado por objetos e outros corpos. Meu corpo encontra-se como "ponto zero" (HUSSERL, I994, p. 52) desse entorno que o cerca. Significa dizer que a variação desse entorno se dá por uma relação direta com a posição espacial do $e u$, e consequentemente, do corpo. Porém, por mais que uma coisa varie de acordo com a posição espacial do eu corporal, "se trata sempre da mesma coisa com idênticas propriedades" (HUSSERL, I994, p. 52).

O corpo apresenta-se como medida de variabilidade de seu entorno. Nessa atitude de experiência, onde cada coisa está situada espacialmente, as vivências também possuem uma determinação espacial. Elas se situam no corpo próprio, possuem uma relação direta com ele. Essas vivências são nossas percepções, recordações, imaginações, volições e qualquer outro sentimento, aquilo que é da ordem do subjetivo, do eu, da consciência. Quando afirmo que tais vivências, nessa atitude natural, são consideradas pertencentes ao corpo orgânico, isso significa afirmar, por exemplo, que minha percepção está diretamente ligada aos meus olhos, bem como minha recordação ao cérebro e minhas sensações aos órgãos dos sentidos. Elas ganham nessa atitude uma existência espacial e são determinadas por uma variação do meu estado corporal. São "dependentes, em certa medida, [...] do corpo e seus estados e processos corporais" (HUSSERL, I994, p. 50) e é impensável considerála sem um vivente corporal, sem um corpo orgânico para tê-las e um corpo próprio para vivê-las.

Como situar, nessa atitude, o outro? $O$ outro não poderia ser dado de outra maneira senão por experiência desse eu situado no espaço e no tempo. Husserl afirma ( I994, p. 5I) que, nessa atitude, é no modo da empatia que conheço e reconheço o outro: "cada eu põe esse outro eu no modo da 'empatia' e com ele encontra também as disposições de caráter e o vivenciar do outro". O outro se dá por uma capacidade que tenho de compreendê-lo e compreender aquilo que dele se apresenta a mim. Se ele realiza uma ação ou esboça uma emoção, compreendo-o, porque possuímos o mesmo corpo orgânico. É a partir da experiência que tenho de meu corpo, daquilo que sinto através dele, dos sentimentos que tenho e das emoções que esboço, que é possível compreender o outro como diferente, mas ao mesmo tempo semelhante a mim. Ele possui e esboça as mesmas reações, os mesmos sentimentos e emoções, mas, ao mesmo tempo, eu não as sinto como as sente, eu não as vivo, é nele que se realizam tais sentimentos e emoções. Ele está presente a mim como um corpo do qual não posso ter experiência direta. Eu o compreendo. 
Pela empatia, o eu próprio "encontra também disposições de caráter e o vivenciar do outro que, sem dúvida, não são dados ou tidos como próprios" (HUSSERL, I994, p. 5I). Eu o apreendo não como centro de um entorno, mas como um ponto do espaço, como um ponto do meu entorno. O corpo do outro varia juntamente com os objetos, da mesma forma que meu corpo varia em relação ao corpo dele. Encontramos o corpo do outro "não através da 'autopercepção' e da recordação, mas por meio da empatia" (HUSSERL, I994, p. 55).

Podemos, então, compreender com mais clareza a crítica de Husserl a esse tipo de atitude e sua proposta filosófica de apreensão da realidade. A questão que se coloca é: que tipo de conhecimento pode-se obter dessa realidade?

Essa questão se fundamenta sobre o modo como se coloca a atitude natural, a saber:

Seus objetos são as coisas justamente no sentido em que são doações da experiência e nos são dadas como coisas em si existentes, que têm lugar determinado e uma extensão no espaço objetivo assim como uma posição e duração na duração objetiva e que se transformam de tal modo, ou não, etc. (HUSSERL, I994, p. 57).

É a partir de uma aceitação tácita da realidade dada na atitude natural, que o homem faz ciência. Os juízos ou resultados científicos obtidos se tornam uma "tese da experiência" (HUSSERL, I994, p.56) e ganham validez absoluta.

As ciências da atitude natural desenvolvem seu conhecimento tendo como objetos a coisa em si mesma determinada espacial e temporalmente relacionada a um eu corporal que é referência da variação da experiência. Ora, visto que as descrições da atitude natural são baseadas naquilo que experimento, cabe indagar qual o fundamento dessas ciências. Se, por um lado, julgo sobre aquilo que me aparece na realidade, fica obscuro o juízo que faço sobre o objeto dado na experiência. A crítica de Husserl se endereça a essa passagem direta da experiência ao entendimento, ou seja, o momento da formação do juízo sobre a experiência. As ciências, afirma Husserl (I994, p. 57), "se remetem ao fundamento último de direito, a doações imediatas da experiência”. Ou seja, os juízos ao mesmo tempo em que são extraídos da experiência, recebem sua validade e evidência da própria experiência. Qual problema? Que essa tese da experiência é sempre uma evidência imperfeita, e, salienta Husserl (I994, p. 56), "todo mundo sabe que a "experiência pode nos enganar [...], não obstante, o experenciado 'não necessita realmente ser'”. Como Descartes, Husserl julga necessário buscar um novo e seguro fundamento para o saber e, como Descartes, julga ser preciso atacar "os próprios princípios em que se apoiava tudo aquilo em que outrora acreditei" (HUSSERL, I994, p. 23)

Husserl, portanto, questiona o critério de verdade das ciências. Sobre qual fundamento constroem um saber? Enquanto ciências que permanecem 
na atitude natural, seu saber é sempre impreciso na medida em que seus juízos são fornecidos pelos sentidos, e se remetem à própria experiência como confirmação de sua validade. A evidência de seus juízos se baseia na adequação com a realidade da qual são predicados.

Para compreender a crítica husserliana, precisamos acompanhar o que diz Husserl sobre o conhecimento de tipo psicológico na atitude natural, pois sua crítica ao estado atual da psicologia como ciência empírica alcança também as ciências empíricas da Natureza, isto é, as ciências fundadas na atitude natural. Da mesma forma que "a ciência natural do físico descreve coisas e as explica a partir de uma regularidade causal” (HUSSERL, I994, p. 58), a psicologia "descreve e explica a partir de uma regularidade causal, as personalidades humanas com seus estados, atos e disposições" (HUSSERL, I994, p. 58). O eu corporal, com suas vivências, não pode descrever aquilo que é psicológico sem deixar de remeter-se ao físico da experiência. Parte-se de "um eu psicológico pertencente ao tempo objetivo, ao mesmo tempo em que pertence ao mundo espacial [...] que se encontra vinculado ao corpo, cujo funcionamento depende os estado e atos psíquicos" (HUSSERL, I994, p. 59). É partindo desse modo de considerar toda realidade que faz o conhecimento psicológico considerar "um mundo enquanto as almas são dos corpos e enquanto o mundo é o da experiência" (HUSSERL, I994, p. 66). Que problema surge para o conhecimento psicológico? Ao partir da atitude natural, a ciência do eu psicologia - adquire uma postura semelhante à das ciências físicas, em ambas a regularidade causal empiricamente constatada é tida como explicação. No caso da psicologia, o eu psicológico é considerado em relação ao corpo orgânico, de maneira que o psíquico passa a ser explicado a partir do corpo físico - um corpo objetivo espacial e temporal ou uma coisa natural - e não a partir do corpo próprio, que é um corpo vivido ou psicológico. Por conseguinte, o resultado é uma indiferenciação entre físico e psíquico, entre o mundo dos objetos e o eu, que se reduz a uma coisa empírica.

Haveria algum conhecimento que se remetesse a algo que não a realidade empírica? Afirma Husserl (I994, p. 6I) que "frente à Natureza e o ao mundo empírico, como também se diz, há mundos ideais, mundos inespaciais, intemporais ou irreais de ideias [...]”. Há aqui uma distinção entre atitude empírica, que me coloca frente ao existente, e atitude do tipo apriórica (HUSSERL, I994, p. 6I), que me coloca frente a objetos ideais. O a priori, tomado em sentido kantiano, diz respeito àquilo que não depende da experiência sensível para ser conhecido. Por isso, Husserl afirma que tal atitude apriórica busca aquilo que é de caráter geral, e não individual. As ciências que partem dessa atitude visam o conhecimento daquilo que não depende da experiência para ser, mas que, por outro lado, é o fundamento para que a experiência seja. Tais ciências realizam uma ontologia da natureza, que busca definir aquilo que é essencial 
aos objetos da natureza. "Essa ontologia da natureza seria um título para todas as disciplinas que correspondem à ideia Natureza ou, em seu caso, às ideias que são constitutivas para tal ideia" (HUSSERL, I994, p. 64). Tomando as matemáticas puras, percebemos que o conhecimento alcançado por ela não depende de nenhuma realidade empírica, ou de nenhum objeto da natureza, para ter sua validade e evidência absoluta. Enquanto a experiência da atitude natural se dá no espaço e no tempo, somente uma ciência pura das idealidades pode nos dizer o que são o espaço e o tempo, ou suas ideias.

Ao enunciar ideias que possuem caráter de generalidades, não falo mais sobre coisas, objetos determinados espacial e temporalmente, não julgo sobre individualidades, mas sobre generalidades. Essas ideias puras não são extraídas da percepção sensível dos objetos individualmente dados na experiência. Elas têm um caráter de generalidade na medida em que dizem respeito não a este ou aquele objeto, mas àquilo que é essencial para que o objeto exista enquanto objeto na natureza. "São coisas diferentes perceber um tom G e, por outro lado, formar ideia G" (HUSSERL, I994, p. 6I). Perceber um tom C diz respeito a percebê-lo enquanto tom de alguma melodia apreendida pelos sentidos percebo este tom nesta melodia. Em contrapartida, a ideia que formo do tom $\mathrm{C}$ me permite distingui-lo de qualquer outro tom. Apreendi a ideia essencial do tom $\mathrm{G}$, aquilo que faz que ele seja um tom $\mathrm{C}$ e não $\mathrm{F}$. É por meio dessa atitude apriórica que se obtém as ideias de espaço, formas espaciais, tempo, duração. Nessa atitude, a validade das proposições não depende das objetividades contingentes próprias da experiência sensível, "as proposições destas disciplinas têm validez - como proposições puras - tanto se se dá o existente, como se não" (HUSSERL, I994, p. 6I).

Ainda que as ciências aprióricas nos deem idealidades, elas se constituem como ciências da Natureza, mas que investigam a ideia da Natureza e não mais objetos físicos. Contudo, esse tipo de atitude não nos fornece o suporte necessário para dar conta do aparecer do objeto mesmo. "Com esse campo de disciplinas aprióricas não temos ainda um nível mais elevado próprio da problemática filosófica" (HUSSERL, I994, p. 66).

Que busca então, Husserl? Que problemática filosófica seria essa? Husserl busca uma nova atitude, que nos daria um conhecimento independente do dado empírico e que não se remeta a este como fundamento. Trata-se de ir além das ciências, sejam empíricas ou puras, porque a ciência opera a partir de pressupostos implícitos, cujos fundamentos ela desconhece e porque não alcança o aparecer das coisas mesmas. A ciência empírica falha porque simplesmente prolonga o objetivismo espontâneo da atitude natural e toma o mundo como mundo existente; a ciência pura ou apriorística, embora rompa com o empirismo, mantém o pressuposto do mundo como mundo possível. Husserl busca um conhecimento da realidade anterior a esse conhecimento do qual a ciência fala. 
"Podemos, certamente, descrever o conceito de mundo que temos antes da Giência, o sentido que tem a humanidade antes da ciência” (HUSSERL, I994, p. 7I). Por isso, é interessante salientar a crítica endereçada aos objetivistas e em especial à escola de Avenarius e sua tentativa de obter um conceito natural de mundo sem recorrer à metafísica, realizar uma "crítica da experiência pura" (HUSSERL, I994, p. 66). Para Husserl, seria um contrassenso tal empreitada, pois, ao investigar a realidade, ao fazer ciência, já se pressupõe tal realidade, há uma pressuposição do mundo, da humanidade e do conceito natural de mundo.

Diante disso, "não há outras formas de olhar" (HUSSERL, I994, p. 74)? "Que houve com a reflexão sobre o pensar mesmo e sobre todas as vivências [...]" (HUSSERL, I994, p. 74)? "O que aconteceu com toda a esfera de conhecimento em sentido subjetivo, em contraposição [...] a seu sentido objetivo?" (HUSSERL, I994, p. 74). Da mesma forma que as ciências puras da Natureza buscam seu a priori, devemos "mostrar a essência de um caráter egológico" (HUSSERL, I994, p. 75).

Há aqui uma mudança no olhar. $\mathrm{Na}$ atitude natural e na atitude científica, seja esta empírica ou pura, nosso olhar se dirige à Natureza (existente para a ciência empírica; possível, para a ciência pura). Nessa nova atitude, o olhar não mais se dirige à Natureza, mas realiza uma reflexão sobre o próprio pensar e as vivências de uma esfera egológica, àquilo que não depende da Natureza para ser. O olhar se volta para a esfera da consciência. Se há um a priori em relação à coisa física, como vimos no caso das ciências matemáticas puras, certamente há um a priori psicológico que "explicita o que pertence à essência ou ao sentido da posição empírica das "almas", da posição dos homens, da posição das vivências enquanto vivências dos homens..." (HUSSERL, I99I, p. I3I).

Qual fundamento dessa nova atitude? Aqui, Husserl (I994, p. 78) lança mão de uma distinção entre modos de ser, entre aquilo que é próprio da consciência e o que é próprio das coisas. Propõe uma "distinctio phaenomenológica". Da mesma maneira que uma coisa não sente dor, ou esboça emoções, nem percebe, nem possui lembranças, essas vivências não podem pertencer ao corpo, pois este é coisa e não é da essência das coisas serem "sentientes" e não é da essência das vivências serem espaciais. "Em si mesma, o cogitare não tem nada que ver com nenhuma res extensa. A essência da cogitatio e a da extensio não tem, enquanto essência, nada que ver uma com outra" (HUSSERL, I994, p. 77). Tomando a distinção clássica, proposta por Descartes, entre res cogitans e res extensa e mantendo a afirmação cartesiana de que entre elas há uma distinção real (o que implica ausência de reciprocidade entre elas), Husserl distingue entre a essência ou sentido das coisas (res extensa) e a essência ou sentido da consciência (res cogitans). Com isso, pretende mostrar que a relação entre uma vivência e uma coisa, ou no caso da atitude natural, entre vivência e corpo, não é uma relação entre essências, pois, enquanto essências distintas, não há entre elas nenhuma ligação. 
Não pertence à essência de uma vivência ser espacial ou extensional. Por que é interessante considerar essa distinctio? Porque possibilitará a Husserl dissolver a conexão empírica entre res cogitans e res extensa. Essa distinção justificará a desconexão que irá ocorrer na redução fenomenológica. O que entra em consideração nessa nova atitude? Iremos

[...] colocar fora de circuito toda posição natural (posição do ser-aí natural) no sentido em que nós estabelecemos considerações científicas nas quais, simplesmente não fazemos uso de nenhuma posição de natureza nem conservamos o valor que se adiciona a ela, que exista ou não uma natureza, um mundo corporal-espiritual em geral (HUSSERL, I99I, p. I37).

$\mathrm{Na}$ atitude natural, as coisas "são imediatamente dadas na experiência, pensadas e determinadas em pensamentos de experiência” (HUSSERL, I994, p. 79). São independentes do que penso delas, independentes de minha percepção e lembrança. Há, afirma Husserl (I994, p. 79), frente a esse em-si da coisa, uma "desvantagem insuperável" no conhecimento que temos dela. Com efeito, "a coisa é dada na experiência, e em seguida não é dada mais, quer dizer, sua experiência é uma doação por exposições, por "aparições" "(HUSSERL, I99I p. I39), um conhecimento que nunca se dá de forma "omnilateral" (HUSSERL, I994, p. 80), "nunca de modo absoluto" (HUSSERL, I994, p. 80). O modo pelo qual o objeto da experiência se dá ao conhecimento é no modo do incompleto e infinito, pois é este "o sentido da objetividade da experiência como tal" (HUSSERL, I994, p. 80), porque, essa experiência, "segundo seu sentido, põe a transcendência" (HUSSERL, I994, p. 80).

É justamente essa transcendência - ou seja, o que tem sua existência em si e por si fora da consciência - posta pela experiência que é preciso evitar e colocar fora de circuito. A transcendência que é preciso desconectar nessa nova atitude é a "transcendência no sentido daquilo que aparece" (HUSSERL, I994, p. Io6). Trata-se de passar à imanência da consciência, colocando fora de circuito; a coisa como inesgotável ou a experiência inesgotável de uma coisa que nunca se dá por inteiro e completamente determinada; a indeterminação essencial da coisa na experiência natural; a coisa empírica como existência em si que não depende da consciência para ser.

Visto que se trata de elaborar um conhecimento puro, em ruptura com o conhecimento empírico, Husserl pretende apresentar um novo modo de conhecimento que não leve em consideração nenhum objeto empírico: "não aceitamos agora como realidade nem um só objeto singular posto na atitude empírica" (HUSSERL, I994, p. 82). O olhar se dirige para os próprios atos da consciência (ou do eu) que anteriormente se dirigiam aos objetos, levando em conta apenas esses atos. Essa atitude denomina-se fenomenológica. 
Se, na atitude natural, os objetos eram dados no espaço e no tempo, na atitude fenomenológica, ao contrário, nenhuma objetividade entra em questão, nenhum juízo obtido pela atitude natural servirá de base para as análises. $\mathrm{Na}$ atitude fenomenológica, realiza-se a "redução fenomenológica" (HUSSERL, I994, p. 83). Isso significa que

Não só deve sair fora de jogo qualquer posição da Natureza com suas coisas no espaço e tempo, e com elas também a posição do corpo próprio e da relação psicofísica que mantêm com ele as vivências, como também a posição do eu empírico que como pessoa é pensado num vínculo com o corpo (HUSSERL, I994, p. 83)

Assim, é-nos dado um novo campo de conhecimento, não mais o das realidades transcendentes à consciência, mas o das realidades na imanência da consciência. A redução versa sobre toda ligação espacial e temporal da consciência ou do eu com as coisas. O eu empírico deverá ser reduzido, suspenso, colocado entre parênteses, e mesmo assim poderemos falar de vivências, pois não as estamos considerando em sua ligação com o corpo ou com um eu empírico.

Devemos observar que, ainda que a atitude fenomenológica verse sobre vivências em seu sentido puro, imanentes à consciência, excluindo assim toda transcendência empírica, é somente a partir da atitude natural, ou da maneira natural de considerar as coisas do mundo, ou nos considerar, que podemos partir para uma nova atitude. O ponto de partida da atitude fenomenológica é a atitude natural.

Se tomarmos o projeto radical da redução fenomenológica de desconectar a consciência de toda transcendência e de todo juízo que se funda na experiência, o eu empírico que encontramos na atitude natural deve necessariamente ser colocado entre parênteses. Nas análises dessa nova atitude, não fazemos nenhum uso da validade das objetividades. Não nego o mundo, simplesmente não recorro mais a ele em minhas análises. A atitude fenomenológica visa a um conhecimento sem nenhum pré-julgamento, nenhuma aceitação tácita da realidade ou do eu. Entretanto, se colocamos entre parênteses, além das objetividades, o eu empírico e toda relação corporal que mantêm com as vivências, como podemos ainda falar em vivências sem um eu? Se não há mais um eu, a que ou a quem correspondem tais vivências? Ou seja, "de quem é a cogitatio, de quem é a consciência pura?" (HUSSERL, I994, p. 90). Quando realizamos a redução fenomenológica, somos colocados frente à pureza das vivências. $\mathrm{O}$ que isso quer dizer? Simplesmente, que não há mais nenhuma dependência ou ligação com a coisa empírica. Assim, podemos falar em uma percepção pura que não dependa mais dos estados corporais, ou uma rememoração pura que não dependa mais do cérebro. Da mesma forma, ao reduzirmos o eu empírico, que se encontra já em relação imediata com o corpo orgânico, encontramos 
algo como um "eu puro". Esse "eu puro" não é uma pré-suposição, um préjulgamento, mas uma consequência direta da redução fenomenológica radical.

Encontrando-se o mundo natural entre parênteses incluindo as coisas e pessoas, com um espaço e um tempo mundanos, para a atitude fenomenológica, pôr o que não está nele como existente significa que a investigação descobre que se dá algo assim como um eu puro, como um tempo puro [...] então é alguma coisa de fenomenológico... (HUSSERL, I994, p. 90).

Após realizarmos a redução fenomenológica, somos conduzidos à contemplação absoluta, à percepção fenomenológica, principal modo de experiência fenomenológica. Pois, mesclado a ele me são dados outros modos, como a expectativa, a rememoração, a retenção e a protensão.

Quando percebo uma coisa na atitude natural e realizo a redução fenomenológica, a coisa que percebo é colocada entre parênteses. O que "sobra" dessa redução é a percepção pura. O objeto que antes eu percebia como objeto real e determinado espacialmente, ganha status de objeto intencional, correlato de um ato intencional, correlato da minha consciência. Esse objeto intencional não é um objeto físico, mas um ser puro, um correlato da consciência em regime de redução.

O que encontramos no conhecimento da percepção em seu estado puro? Imediatamente se dá sua forma temporal: "a percepção é um ser que dura" (HUSSERL, I994, p. 96). Mas, se o objeto é dado nessa duração, como posso apreendê-lo de maneira absoluta? Podemos apreendê-lo porque a percepção se dá como "unidade de uma duração" (HUSSERL, I994, p. IIO) e "cada fenômeno reduzido se oferece como um ser que dura e precisamente como autopresença que dura" (HUSSERL, I994, p. IIO). Como nasce essa unidade? Como síntese intencional, operação essencial da consciência pura.

A percepção tem um ponto fluente de autopresente originário (originärer Selbstgegenwart) e, além disso, um horizonte de doação "retencional" como recém-passado e, do mesmo modo, um horizonte imediato de futuro de doação potencial. Se uma percepção está transcorrendo, entra em seu lugar a retenção que, seguindo viva um lapso de tempo na forma de "obscurecimento" progressivo, finalmente se obscurece por completo (HUSSERL, I994, p. 96).

Cada momento de uma melodia escoa para um passado que não é percebido atualmente, mas que permanece enquanto horizonte da percepção atual: da mesma maneira espera seu desdobramento em uma protensão, que logo se torna presente para escoar ao passado. Eu compreendo a melodia, pois há uma síntese desses três momentos na consciência. A percepção da melodia 
não poderia ocorrer sem essa retenção de um presente que já não é, e sem essa expectativa do que está por vir. É sob esse horizonte do passado retido e essa expectativa do por vir que é possível a percepção.

Esses modos de doação ${ }^{2}$ do fenomenologicamente dado como percepção, retenção e protensão abrem outros modos, como a rememoração, que diz respeito ao presente retido, e a expectativa, que se refere àquilo que ainda não é atualmente, que está por vir. Também sobre esses modos de doação podemos executar a redução fenomenológica e apreendê-los em sua forma pura. Os modos de doação, como a retenção e a protensão são "intencionados e conscientes em certo modo" (HUSSERL, I994, p. IOI), pois formam uma espécie de horizonte que possibilita o aparecimento do imediatamente dado e consciente. Tais modos de doação constituem, de certa forma, uma "transcendência na imanência fenomenológica" (HUSSERL, I994, p. IO2). Como vimos, a transcendência que desejamos suspender, ou colocar entre parênteses, é de coisas ou pessoas que possuem existência fora do âmbito da consciência, é a da coisa em si posta pela atitude natural. No caso da retenção e da protensão, há uma transcendência dos objetos postos por ela, mas tal transcendência que se realiza na imanência da consciência, ou seja, não se trata de uma coisa em si, espacial e temporal, e sim de uma vivência que escoa. Podemos chamá-las de transcendentes porque, de certa maneira, escapam à apreensão atual da consciência, como vimos no caso da percepção, mas permanecem como aquilo que pode ser retomado e tornado consciente novamente.

Da mesma maneira que podemos executar a redução fenomenológica para a percepção, retenção, expectativa, rememoração e qualquer outro ato da consciência, podemos exercer a redução sobre a experiência que na atitude natural me dava o outro: a empatia.

$\mathrm{Na}$ atitude natural, o outro aparece como tendo atos semelhantes aos meus, vendo coisas semelhantes às que eu vejo, mas a empatia não é sentir como o outro sente e sim compreender seu sentimento. Em regime de redução, na empatia, não mais consideraremos a posição que o eu ocupa, desconsideraremos da mesma maneira o outro enquanto eu corporal, apreenderemos esse ato em sua pureza e da forma como ele se apresenta à consciência. Como a percepção, a

2 A consciência, para Husserl, é doadora de sentido. Com a redução fenomenológica, a realidade corporal se torna correlato de uma unidade de múltiplas aparições que é constituída através da síntese dos momentos de apresentação do objeto. As intuições sensíveis, características da atitude natural, são, por essência, imperfeitas, podendo ser confirmadas ou substituídas por outras mais perfeitas. Husserl critica esse tipo de pensamento que considera a doação da experiência como a doação absoluta, pensamento que leva as Ciências da natureza a considerarem a coisa dada em si mesma, como é dada na experiência sensível. 
empatia se dá no fluxo temporal da consciência. Mas, por essa maneira, o outro me aparece por meio de uma impossibilidade de apreensão dele numa unidade de retenções. Precisamente aí o outro aparece como verdadeiramente outro.

Porém, indaga Husserl (I994, p. I22), "não chegamos nunca a outro eu fenomenológico?" (HUSSERL, I994, p. I22). É possível que meus atos intencionais visem outra consciência que não a minha? Para Husserl (I994, p. I84), "por princípio, uma e outra consciência só podem entrar em relação através da empatia”. (HUSSERL, I994, p. I84) Na percepção de um objeto, mantenho em recordação seus momentos, e assim minha percepção do agora escoa ao passado e se mantém na retenção, assim compreendo o que estou percebendo. Na percepção do outro, ao contrário, "não posso nunca ter a recordação de algo que pertença à primeira (consciência)" (HUSSERL, I994, p. I84). O outro me aparece enquanto outro, justamente pela incapacidade que tenho de realizar uma apreensão de sua consciência.

\section{Referências Bibliográficas}

GHAUÍ, Marilena. Experiência do pensamento. Martins Fontes, 2002.

DESGARTES, René. Meditações sobre filosofia primeira, Unicamp, 2008

HUSSERL, Edmund. Idées directrices pour une phénoménologie et une philosophie phénoménologique pures. Gallimard, I989. , Problemas fundamentales de la fenomenología, Alianza Editorial, I994. Problèmes Fondamentaux de la phénoménologie, PUF, I99I.

MOURA, G.A.R. de. Crítica da razão na fenomenologia, Nova Estella, I989. Racionalidade e Crise. Discurso Editorial. 200I.

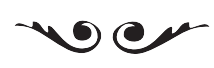

Rafael Gargano é graduando em Filosofia pela USP.

E-mail: rafael.gargano@usp.br 